\title{
What happened to life expectancy in Spain in the 1980s?
}

\author{
Laurent Chenet, Martin McKee, Angel Otero, Inma Ausin
}

\begin{abstract}
Background-Life expectancy at birth in Spain improved between 1972 and 1982, by 2.5 years for males and 3.2 years for females. This slowed considerably in the following decade, with increases of only 0.5 and 1.7 years respectively.

Objective-To determine the causes of death that have been responsible for the failure by Spain to maintain in the 1980s and 1990s the rate of improvement in life expectancy seen during the 1970 s.

Design-Data from WHO mortality tapes grouped in a series of clinically meaningful categories were used to calculate the contribution of each category, in five year age groups, to the changing life expectancy at birth in the two periods.

Setting-Spain.

Results-The trend in life expectancy at birth in Spain over this 20 year period can be considered to have two components, both with important consequences for public health policy. Underlying trends include a steady negative contribution from respiratory cancer in men and a reduction in cardiovascular disease. More recent trends include a considerable deterioration in deaths among young adults, most notably from accidents and, possibly, AIDS.

Conclusion-The failure to maintain the rate of earlier gains in life expectancy in Spain can be attributed largely to a few conditions, although these may indicate less obvious underlying problems. These findings have important consequences for prioritising public health policies.
\end{abstract}

$(\mathcal{F}$ Epidemiol Community Health 1997;51:510-514)

European Centre on Health of Societies in Transition, London School of Hygiene and Tropical Medicine,

Keppel Street, London WC1E 7HT

L Chenet

$\mathrm{M} \mathrm{McKee}$

Centro Universitario de Salud Publica, 28006 Madrid, Spain A Otero

I Ausin

Correspondence to: Professor M McKee.

Accepted for publication May 1997
In studies of the health of populations, the countries of southern Europe have been noteworthy because of their relatively good performance, as assessed by measures of health status. Spain, Italy, and Greece have some of the longest life expectancies at birth in the European Union. Several reasons have been advanced to explain this, with the role of the Mediterranean diet attracting particular attention. But an examination of recent health indicators suggests that this impression of a healthy Mediterranean environment may no longer be justified, at least in the case of Spain. In the 10 years between 1982 and 1992, male life expectancy at birth increased by only 0.5 years, a much lower figure than the 2.5 year improvement seen in the preceding 10 years period (fig
1). ${ }^{1}$ Indeed, if the period between 1976 and 1982 is considered alone, the rate of increase was even greater.

Composite demographic figures, such as life expectancy at birth, simply indicate the existence of a problem, such as a change in trends, but say nothing about its causes. This paper is a first step in advancing our understanding of what has been happening in Spain since the 1970 s. It identifies the contribution of deaths from specific causes and at different ages to the change of in life expectancy at birth between 1972 and 1982 inclusive on the one hand, and 1982 and 1992 inclusive on the other. The later period has been chosen to capture the period from when life expectancy ceased increasing to when the most recent data are available. The former period is of the same duration prior to this.

\section{Methods}

The study analysed mortality data from the World Health Organization mortality tapes, classified according to the 8th and 9th revision of the International Classification of Diseases (ICD-8, ICD-9). For the year 1972, a proportional repartition of deaths at unknown ages was performed. Life tables for both sexes were constructed using standard techniques. The abbreviated causes of deaths were brought together to create a smaller series of clinically meaningful categories (table 1). These were selected using the criteria of numbers of deaths and association with known risk factors. The contribution of each of these categories at each 5 year age group (although the 0 to 1 age group was analysed separately) to the difference in life expectancy at birth at the beginning and end of the two periods, and for each sex, was calculated using the same approach as that developed by Pollard. ${ }^{23}$ This is summarised in the appendix and described in detail elsewhere. ${ }^{4}$

\section{Results}

The contributions of each of the groups of cause of death in each age band to the change in overall life expectancy at birth between the selected years are shown in tables 2-5. Taking males first, during the 1970 s decreasing deaths in every age group contributed positively towards the increase in overall life expectancy, but not equally - the improvement in mortality was most prominent among infants and the elderly. Although there were also improvements between the ages of 1 and 59, these were somewhat smaller with few age groups contributing more than a tenth of a year. When exam- 


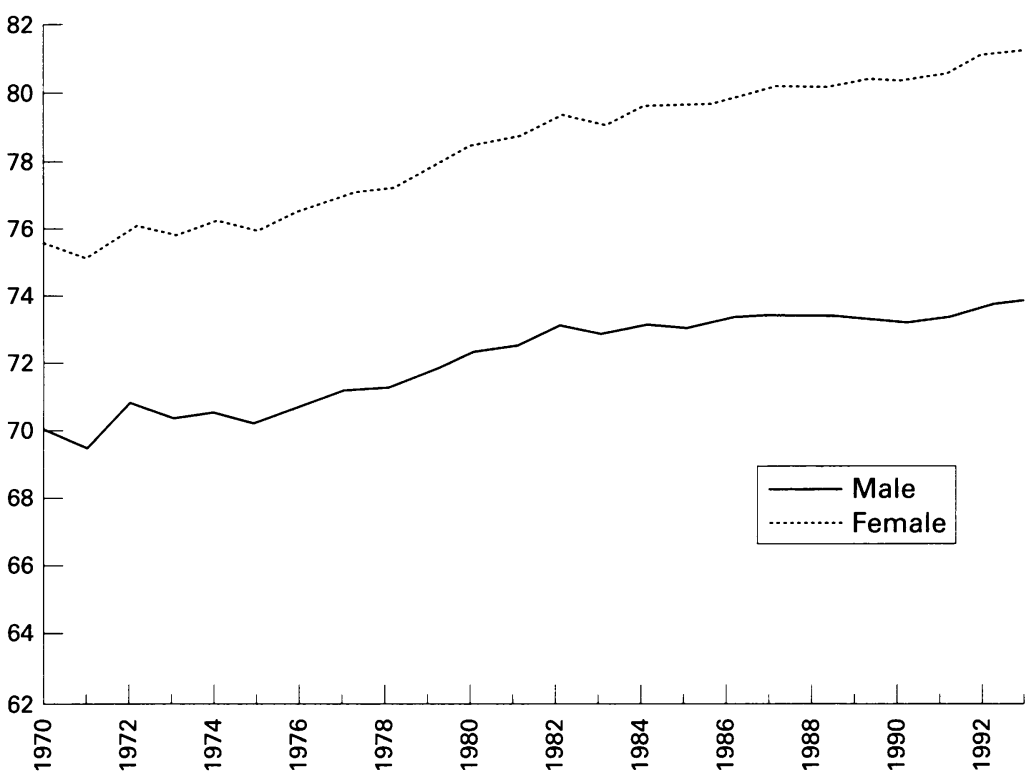

Figure 1 Life expectancy at birth in Spain, 1970-93. Source: WHO Health for All Database

ined by cause of death, apart from the perhaps surprising negative contribution from congenital and neonatal diseases at a time of falling infant mortality, the only other significant negative contribution was that of cancer of the respiratory system, a phenomenon seen in many industrialised countries at that time, reflecting an earlier growth in smoking rates (table 2).

The picture for the period 1982-92 is very different, with a striking negative contribution

Table 1 Disease categories used in study

\begin{tabular}{ll}
\hline Disease category & Abbreviated ICD-9 codes \\
\hline Infectious diseases & $001-139$ \\
Respiratory cancer & $161-162$ \\
Other cancer & $140-157,170-239$ \\
Cerebrovascular diseases & $430-438$ \\
Cardiovascular diseases & $390-429,440-459$ \\
Respiratory diseases & $460-519$ \\
Accidents & E800-E949, E960-E999 \\
Congenital/ perinatal & \\
$\quad$ diseases & $740-799$ \\
Suicide & E950-E959 \\
Cirrhosis & 571 \\
Other diseases & $240-389,520-570,572-739$, \\
& $780-799$ \\
\hline
\end{tabular}

KEY POINTS

- The improvements in life expectancy in Spain during the 1970 s were not maintained in the 1980s.

- This is largely due to a combination of long term increasing trends in diseases such as lung cancer in men and more recent increases in deaths of young men, many of which are the result of accidents and, probably, AIDS.

from deaths among young adults (table 3 ). Two categories of cause of death are responsible for this poor performance-accidents and violent deaths and the "other" category. The latter is a loose grouping of causes of death not classified elsewhere, but careful examination of the data shows that the main contributor to the increase in this category is the B18 category (ICD-9 tabular list), "endocrine and metabolic diseases, immunity disorders", a category that commonly contains many deaths from AIDS. That AIDS might explain this rise is supported by the related observation that infectious diseases also make a negative contribution in the age groups $25-44$ and by the fact that Spain now has the highest AIDS incidence rate in Europe. $^{5}$

At older ages there have been further improvements, despite the negative contribution of cancers, especially of the respiratory system, which continue to contribute a decrease of about 0.2 of a year to overall life expectancy. Overall, 0.7 years of life expectancy at birth can be accounted for by decreasing deaths above the age of 50, mainly due to cardiovascular disease. However, this substantial achievement is totally annulled by the corresponding loss of 0.7 years from increasing deaths between the age of 15 and 49 . Consequently it can be considered that the remaining improvement in life expectancy has been achieved through falling deaths in infancy and childhood.

For females, the period between 1972 and 1982 was characterised by substantial improvements on all fronts. Nearly half a year of life

Table 2 Contribution to change in male life expectancy at birth in Spain, 1972-82 (values, years)

\begin{tabular}{|c|c|c|c|c|c|c|c|c|c|c|c|c|}
\hline $\begin{array}{l}\text { Age } \\
\text { group }\end{array}$ & Infectious & $\begin{array}{l}\text { Respiratory } \\
\text { cancer }\end{array}$ & $\begin{array}{l}\text { Other } \\
\text { cancer }\end{array}$ & $\begin{array}{l}\text { Cerebrovascular } \\
\text { diseases }\end{array}$ & $\begin{array}{l}\text { Other } \\
\text { cardiovascular } \\
\text { diseases }\end{array}$ & $\begin{array}{l}\text { Repiratory } \\
\text { diseases }\end{array}$ & $\begin{array}{l}\text { Accidents } \mathcal{E} \\
\text { violence }\end{array}$ & $\begin{array}{l}\text { Congenital } \\
\text { and perinatal }\end{array}$ & Suicide & Cirrhosis & Other & Total \\
\hline 0 & 0.155 & 0.000 & 0.004 & 0.021 & 0.030 & 0.240 & -0.004 & -0.123 & 0.000 & -0.001 & 0.156 & 0.478 \\
\hline $1-4$ & 0.030 & 0.000 & 0.003 & 0.008 & 0.018 & 0.051 & 0.030 & -0.005 & -0.001 & 0.001 & 0.060 & 0.194 \\
\hline $15-34$ & 0.013 & -0.004 & 0.005 & -0.002 & 0.017 & 0.008 & 0.095 & 0.003 & -0.022 & -0.001 & 0.079 & 0.190 \\
\hline $35-64$ & 0.127 & -0.133 & -0.008 & 0.072 & 0.102 & 0.129 & 0.117 & 0.003 & 0.006 & -0.005 & 0.253 & 0.661 \\
\hline $65+$ & 0.038 & -0.101 & 0.025 & 0.254 & 0.281 & 0.197 & 0.017 & 0.000 & 0.006 & 0.022 & 0.230 & 0.969 \\
\hline All & 0.362 & -0.238 & 0.028 & 0.353 & 0.448 & 0.624 & 0.254 & -0.122 & -0.011 & 0.017 & 0.777 & 2.493 \\
\hline
\end{tabular}

Table 3 Contribution to change in male life expectancy at birth in Spain, 1982-92 (values, years)

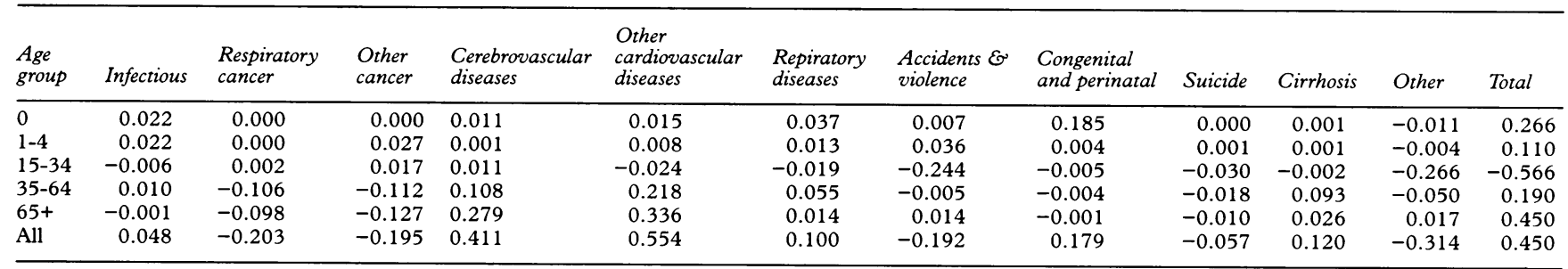


Table 4 Contribution to change in female life expectancy at birth in Spain, 1972-82 (values, years)

\begin{tabular}{|c|c|c|c|c|c|c|c|c|c|c|c|c|}
\hline $\begin{array}{l}\text { Age } \\
\text { group }\end{array}$ & Infectious & $\begin{array}{l}\text { Respiratory } \\
\text { cancer }\end{array}$ & $\begin{array}{l}\text { Other } \\
\text { cancer }\end{array}$ & $\begin{array}{l}\text { Cerebrovascular } \\
\text { diseases }\end{array}$ & $\begin{array}{l}\text { Other } \\
\text { cardiovascular } \\
\text { diseases }\end{array}$ & $\begin{array}{l}\text { Repiratory } \\
\text { diseases }\end{array}$ & $\begin{array}{l}\text { Accidents } \mathcal{E} \\
\text { violence }\end{array}$ & $\begin{array}{l}\text { Congenital } \\
\text { and perinatal }\end{array}$ & Suicide & Cirrhosis & Other & Total \\
\hline 0 & 0.132 & 0.000 & -0.002 & 0.023 & 0.037 & 0.246 & -0.003 & -0.123 & 0.000 & -0.001 & 0.111 & 0.420 \\
\hline $1-4$ & 0.039 & 0.000 & 0.016 & 0.008 & 0.009 & 0.048 & 0.016 & 0.002 & 0.000 & -0.001 & 0.068 & 0.204 \\
\hline $15-34$ & 0.020 & 0.003 & 0.012 & 0.003 & 0.038 & 0.017 & 0.009 & -0.002 & -0.005 & 0.003 & 0.094 & 0.192 \\
\hline $35-64$ & 0.053 & 0.007 & 0.098 & 0.123 & 0.268 & 0.077 & 0.045 & 0.003 & -0.001 & 0.024 & 0.243 & 0.938 \\
\hline $65+$ & 0.028 & -0.004 & 0.080 & 0.385 & 0.431 & 0.249 & 0.005 & 0.000 & -0.001 & 0.031 & 0.273 & 1.477 \\
\hline All & 0.271 & 0.005 & 0.203 & 0.541 & 0.783 & 0.637 & 0.071 & -0.120 & -0.007 & 0.056 & 0.789 & 3.230 \\
\hline
\end{tabular}

Table 5 Contribution to change in female life expectancy at birth in Spain, 1982-92 (values, years)

\begin{tabular}{|c|c|c|c|c|c|c|c|c|c|c|c|c|}
\hline $\begin{array}{l}\text { Age } \\
\text { group }\end{array}$ & Infectious & $\begin{array}{l}\text { Respiratory } \\
\text { cancer }\end{array}$ & $\begin{array}{l}\text { Other } \\
\text { cancer }\end{array}$ & $\begin{array}{l}\text { Cerebrovascular } \\
\text { diseases }\end{array}$ & $\begin{array}{l}\text { Other } \\
\text { cardiovascular } \\
\text { diseases }\end{array}$ & $\begin{array}{l}\text { Repiratory } \\
\text { diseases }\end{array}$ & $\begin{array}{l}\text { Accidents } \mathcal{E} \\
\text { violence }\end{array}$ & $\begin{array}{l}\text { Congenital } \\
\text { and perinatal }\end{array}$ & Suicide & Cirrhosis & Other & Total \\
\hline 0 & 0.019 & 0.000 & 0.002 & 0.006 & 0.006 & 0.024 & 0.003 & 0.158 & 0.000 & 0.001 & 0.006 & 0.225 \\
\hline $1-4$ & 0.010 & 0.000 & 0.011 & 0.003 & 0.010 & 0.011 & 0.005 & -0.001 & 0.000 & 0.002 & 0.003 & 0.053 \\
\hline $15-34$ & -0.002 & -0.001 & 0.020 & 0.007 & 0.020 & 0.003 & -0.051 & 0.000 & -0.002 & 0.004 & -0.065 & -0.066 \\
\hline $35-64$ & 0.006 & 0.002 & -0.015 & 0.105 & 0.178 & 0.033 & 0.009 & -0.006 & -0.002 & 0.040 & 0.082 & 0.433 \\
\hline $65+$ & -0.009 & 0.004 & -0.044 & 0.476 & 0.486 & 0.101 & 0.038 & -0.002 & -0.004 & 0.008 & 0.029 & 1.083 \\
\hline All & 0.023 & 0.005 & -0.026 & 0.598 & 0.700 & 0.172 & 0.004 & 0.150 & -0.008 & 0.055 & 0.056 & 1.728 \\
\hline
\end{tabular}

Note: Totals are subject to rounding. More detailed versions of tables 2-5, including data by 5 year age band, are available on request from the authors.

expectancy was gained by reduced mortality among infants, while the older ages experienced large gains through reduced mortality from cardiovascular diseases and some malignant neoplasms (table 4). During the period 1982-92 there was overall virtually no improvement between the ages of 1 and 49. However, there were further improvements for infants and elderly (table 5). Overall, there was a small improvement in deaths from accidents and cirrhosis, the former in marked contrast to the situation for men. The "other" category once again contributed negatively in the age groups 20-39, again possibly due to increasing deaths from AIDS. The positive contribution in the 1970s from falling deaths from cancer was eliminated.

\section{Discussion}

Throughout the period 1972-92, life expectancy increased in Spain for both sexes. However, there was a marked slowing down during the second decade, especially for men. Although this situation has been noted by some Spanish authors, ${ }^{6}$ it has received relatively little attention in international journals.

Among both men and women, decreases in cardiovascular mortality at older ages made large contributions to the increase in life expectancy. In contrast, accidents and violence among young adults made major negative contributions. There were also substantial increases in "diseases of the endocrine and immune systems", a category which often contains AIDS deaths.

Although there is no reason to doubt the overall data on life expectancy, it is possible that the analysis offered here could be subject to artefact due to changes in coding practice and in particular to the change from the 8th to the 9th International Classification of Disease. The use of these broad diagnostic categories should ensure that this has little effect, ${ }^{7}$ except possibly the observed negative contribution from congenital and perinatal deaths.

The trends in life expectancy between 1972 and 1992 can be considered as having two components. The first are those long term trends that have persisted through the entire period with little overall change, such as the persistent negative consequences of respiratory cancers in men and positive contributions from cerebrovascular and cardiovascular diseases. The first of these emphasises the importance of policies to address tobacco consumption in Spain. Although the level of respiratory cancer among women is low, something that has been noted elsewhere, ${ }^{8}$ it has been shown in a casecontrol study that this is consistent with their smoking history. ${ }^{9}$ Unfortunately, this situation seems unlikely to persist as there has been a considerable increase in the proportion of female smokers since the 1970s, from $18-26 \% .{ }^{1}$ The other changes suggest that concerns about the impact of moves away from a traditional Mediterranean diet may so far be premature, although we cannot exclude the possibility that any effects may emerge in the future. The reasons for these falls remain poorly understood and require further research. $^{10}$

Reductions in deaths from other respiratory diseases made an important contribution to improving life expectancy in the first period, but had very little effect in the second period. This is a pattern seen in many other countries and reflects the long term reduction in mortality from many infectious diseases.

The second component comprises those conditions for which trends have changed during this period. For men, who have experienced the greater overall slowing of the rate of increase of life expectancy, the largest contributors have been deaths from accidents and from "other" causes. These have affected young adults of both sexes though disproportionately so young men.

The ICD-9 classification does not contain specific codes for AIDS related deaths. However, as well as the increase in deaths from "diseases of the endocrine and immune systems", there has also been an increase in mortality from infectious diseases at younger age group that is consistent with the idea that the spread of HIV/AIDS is responsible for the increase in the "other" category. In 1992, 
nearly 5000 deaths from AIDS were reported in Spain. This is remarkably similar to the figure for the increase in deaths between 1982 and 1992 in the category "diseases of the endocrine and immune system" of 4963, 3499 of whom were male and 1464 female, a division reflecting the gender distribution of AIDS deaths.

The most striking finding of this study is the deterioration in the mortality experience of young adults, apparently due, to a considerable extent, to accidents and AIDS. This is consistent with a more detailed study from Madrid that obtained information from AIDS registers, the police, and forensic medical services. It found that the commonest causes of deaths among those aged 15-39 in 1990-91 were AIDS, narcotic related deaths, and traffic accidents. ${ }^{11}$ Another study of trends in Madrid in death rates over the period 1986-92 also noted the importance of accidents and AIDS, with a slight decrease in the former but acceleration in the rate of increase of the latter in the early $1990 \mathrm{~s}^{12}$

The apparent impact of AIDS on the change in life expectancy is substantial but not surprising given that Spain now has the highest incidence rate of AIDS in Europe. By the end of June 1996, over 43000 AIDS cases had been reported $^{13}$ out of a population of 39 million. Moreover, the epidemic does not show any signs of abating, with forecasts predicting between 7000 and 9000 new cases per year. In Spain, as in the other southern countries of Europe, in most of the reported cases (66\%) transmission was through injecting drug use. Recent estimates put the number of HIV positive people at 150000 at the end of 1993, with an increase amongst the heterosexual population. ${ }^{14}$

The public health importance of accidents, and especially road traffic accidents, has been the subject of much research in Spain. The 1993 national health survey reported that $7.8 \%$ of the population had had a road traffic accident in the preceding year, and the frequency was highest among males aged $11-30 .{ }^{15}$ One study has noted the much greater contribution of motorcycle accidents in Spain compared with other European countries. ${ }^{16}$ Other studies have highlighted the importance of alcohol in road traffic accidents. One survey of those on the national register of those with driving licences, albeit with a very low response rate, reported that $14.3 \%$ had driven while drunk in the preceding year. ${ }^{17}$ The same survey also reported a high frequency of use of illicit drugs, with $3 \%$ of respondents reporting having driven after taking them. ${ }^{18}$ Regular drug users were significantly more likely to have been involved in an accident. The importance of alcohol has also been noted in a study which reported a steady increase throughout the 1980 s in alcohol related deaths. ${ }^{19}$

Deaths from suicide require comment as a recent study noted that while Spanish men and women had the second lowest rates of suicide in western Europe (defined as the 15 EU countries plus Iceland, Norway and Switzerland), this is no longer the case due to a sharp increase in suicide rates: $60 \%$ for women and $50 \%$ for men over the period $1981-91 . .^{5}$ Our analysis provides more insight into this phenomenon. While suicide rates have been increasing, they still have no significant impact on overall life expectancy. However, the age distribution of the increase is important, particularly for men. While the increase concerned mostly young men between 1972 and 1982, this has now spread to all ages and especially the elderly. While the study of suicide deaths is fraught with possible reporting biases, suicide remains a strong indicator of a lack of psychosocial well being which is increasingly being recognised as an important determinant of overall health. ${ }^{20}$

This study goes some way to understanding the nature of the failure to maintain the improvements in life expectancy seen in Spain during the 1970s and identifies the priority areas for public health policies. Inevitably, it raises more questions than it answers and highlights several areas requiring further study. In particular, by concentrating on medically defined causes of death it does not address possible underlying factors such as changes in social cohesion, income inequalities and related factors. It is planned to address these issues by taking advantage of the marked regional variations which, although not reported here, are known to exist. ${ }^{21}$

Funding: this study is supported by the European Commission FoPERN this study is supported by the European Commission COPERNICUS Programme (CRB 3510 PL 924074$)$ ).

Conflicts of interest: none.

1 World Health Organization. Health for all database. Copenhagen, WHO, 1997.

2 Pollard JH. The expectation of life and its relationship to mortality. Fournal of the Institute of Actuaries 1982; 9: $225-40$

3. Pollard JH. Cause of death and expectation of life: some international comparisons. In: Vallin J, D'Souza S, Pallon A eds. Measurement and analysis of mortality: new approaches. Liege: Oxford University Press, 1987;269-91

4 Chenet L, McKee M, Fulop N, Bojan F, Brand H, Hort A Kalbarczyk P. Changing life expectancy in central Europe: is there a single reason? F Public Health Med 1996; 18: 329 36.

5 World Health Organization. Highlights on health in Spain. Copenhagen: World Health Organization. Regional Office for Europe, 1996.

6 del Valle-Gomez MO, Lopez-Gonzalez ML, ArcosGonzalez PI, Cueto-Espinar A. Analisis de los anos potenciales de vida perdidos por cancer en Asturias y Espana. ciales de vida perdidos por cancer en

7 Office of Population Censuses and Surveys. Mortality statistics. Comparison of 8th and 9 th revisions of the international classification of diseases. Series DHI no 10. London: OPCS, 1983.

8 Rodriguez-Suarez V, Alvarez-Sanchez G, Diaz-Ruisanchez E, Garcia-Tardon A. Tendencia de la mortalidad por cancer de pulmon en Asturias (1976-1989). Rev Sanid Hig Publica 1993; 67: 465-74.

9 Agudo A, Barnadas A, Pallares C, et al . Lung cancer and cigarette smoking in women: a case control study in Barcelona (Spain). Int f Cancer 1994; 59: 165-69.

10 Banegas-Banegas JR, Villar-Alvarez F, Martin-Moreno JM, Rodriguez-Artalejo F, Gonzalez-Enriquez J. Relevancia de la mortalidad por enfermedades del aparato circulatorio in Espana. Rev Clin Esp 1992; 190: 321-27.

11 Sarasqueta-Eizaguirre C, Zunzunegui-Pastor MV. Principales causas de mortalidad en jovenes en la Communidad Autonoma de Madrid: 1990-1991. Gac Sanit 1994; 8: 11721.

12 Alberdi-Odriozola JC, Diaz-Jiminez L. Modelización de la mortalidad diaria en la Communidad de Madrid de 1986 a 1991. Gac Sanit (in press)

13 AIDS surveillance in Europe. Quarterly report no 60, 31 June 1996. Paris: European Centre for the Epidemiological monitoring of AIDS.

14 AIDS surveillance in Europe. Quarterly report no 44, 31 Dec 1994. Paris: European Centre for the Epidemiological monitoring of AIDS

15 Prada C, Prada R, del Rio MC, Alvarez FJ. Accidentes de trafico en la poblacion espanola. Med Clin Barc 1995; 105: $601-4$. 
16 Plasencia A, Borrell C, Anto JM. Emergency department and hospital admissions and deaths from traffic injuries in Barcelona, Spain. A one year population based study. Accident Analysis and Prevention 1995; 27: 591-600.

17 Alvarez FJ, del Rio MC, Prada R. Drinking and driving in Spain. F Stud Alcohol 1995; 56: 403-7.

18 del Rio MD, Javier-Alvarez F. Illegal drug taking and driving: patterns of drug taking among Spanish drivers. driving: patterns of drug taking anor
Drug Alcohol Depend 1995; 37: 83-6.

19 Prada-Puentes C, Del Rio-Gracia MC, Yañez JL, AlvarezGrada-Puentes C, Del Rio-Gracia MC, Yañez JL, AlvarezGonzalez FJ. Mortalidad relacionada con el consumo de
alcohol en España: 1981-1990. Gac Sanit 1996; 10: 161-8. 20 Wilkinson R. Unhealthy societies. London: Routledge, 1996. 21 Castillo-Catalan J, Tello-Anchuela O, Sanchez-Diaz MF Evolucion del patron epidemiologico de los casos de sida en Espana. Gac Sanit 1995; 9: 159-65.

\section{Appendix}

METHOD OF COMPARING THE CONTRIBUTION OF DEATHS IN AGE GROUPS AND FROM SPECIFIC CAUSES TO DIFFERENCES IN LIFE EXPECTANCY IN TWO POPULATIONS

Designating life expectancy at birth for populations 1 and 2 as $\mathrm{e}_{0} 1$ and $\mathrm{e}_{0} 2$, the difference between the two life expectancies can be written:

$e^{1}{ }_{0}-e_{0}^{2}=\sum n\left({ }_{n} m^{(I)}{ }_{x}{ }^{1}-m_{n} m^{(I)}{ }_{x}^{2}\right) w_{x} w_{x}=1 / 2\left({ }_{x} p_{0}^{2} e^{l}{ }_{x}+{ }_{x} p_{0}^{l} e^{2}{ }_{x}\right)$ where ${ }_{n} m_{x}(I)$ is the central mortality rate for cause $I$ between age $x$ and $x+n$.

The weight $w_{x}$ is given by the formulae: where ${ }_{x} p_{0}$ is the life table probability of surviving from birth to age $x$ and $e_{x}$ the life expectancy at age $x$, that is the mean numbers of years left.

This could also be written as:

$e_{0}^{2}-e_{0}^{l}=\sum_{x} \sum_{I}\left(Q_{x}^{(I)}{ }^{l}-Q^{(I)}{ }_{x}^{2}\right) w_{x}$ with:

$Q_{x}=-1_{n}\left(1_{x+n} / 1_{x}\right)$

where $1_{x}$ is the life table number of people alive at age exact $x$.

The quantities $\left(Q_{x}^{(I)}{ }^{l}-Q_{x}^{(l)}{ }^{2}\right) w_{x}$

give the weight of each cause in the difference observed between the two life expectancies.

The sum over all ages gives the total contribution for each cause I in that difference while the sum over causes would give the relative weight of mortality at each age $x$. 